\title{
Original
}

\section{Animal Model of Trigeminal Neuralgia Induced by Chronic Constriction Injury Applied to the Ophthalmic Nerve in the Rat}

\author{
Kazuo Hanakawa, Takao Sato*, Tadashi Hisamitsu* \\ and Kiyoshi Matsumoto
}

\begin{abstract}
We attempted to produce an animal model of trigeminal neuralgia by chronic nerve constriction injury (CCI) and investigated the time course of pain thresholds in the chronic state. Adult male Wistar rats (250 to $300 \mathrm{~g}$ ) were used in these experiments. All rats were anesthetized with pentobarbital before surgery. Two ligatures $2 \mathrm{~mm}$ apart were made loosely around the unilateral supraorbital nerve with 4-0 silk $(n=21)$. Control animals underwent a sham operation $(n=6)$. In the ligation group, carbamazepine was administered intraperitoneally to 15 rats every day for 10 days from the 10th postoperative day. The sham group $(n=6)$ and the ligation group $(n=6)$ to which carbamazepine was not administered were observed for 40 days after the surgery. Heat and pressure stimulation tests wer performed on these animals. The carbamazepine group $(n=15)$ was observed for 20 days and heat stimulation was performed on this group. Both the avoidance latency to heat stimulation and the avoidance threshold to pressure stimulation were significantly lower on the CCI operation side than on the intact side. The short latency and low threshold lasted for 40 days. In the carbamazepine group the latency of the avoidance response to heat stimulation on the intact side was dose-dependently prolonged. However, on the CCI side $5 \mathrm{mg} / \mathrm{kg}$ carbamazepine had the same effect as $10 \mathrm{mg} / \mathrm{kg}$. We believe this to be the first study of neuralgia in the region of the supraorbital nerve and of the estimation of the therapeutic effect of carbamazepine against chronic neuropathic pain. The model is easy to produce and might be useful for investigating the pathophysiology, etiology, and treatment of trigeminal pain.
\end{abstract}

Key words: trigeminal neuralgia, chronic constriction injury, neuropathic pain, carbamazepine

\section{Introduction}

Our knowledge of the neuropathogenesis of trigeminal neuralgia is limited, because animal models representing trigeminal neuralgia in humans are few. In 1988, Bennett and Xie reported a model of peripheral mononeuropathy ${ }^{1)}$. They applied four loose chromic gut ligatures around the rat sciatic nerve and were able to induce nocifensive responses to stimuli that do not normally cause such behaviors. They called this a chronic constriction

Department of Neurosurgery, Showa University School of Medicine, 1-5-8 Hatanodai, Shinagawa-ku, Tokyo 142, Japan.

* Department of Physiology, Showa University School of Medicine. 
injury (CCI) model. After their report appeared, peripheral neuropathic research increased significantly ${ }^{2-9)}$. However, most studies were of sciatic neuralgia. To study the pathophysiologic changes and etiology of trigeminal neuralgia, we used the CCI method to produce an animal modelo $\mathrm{f}$ trigeminal neuralgia and to follow changes in pain thresholds.

Furthermore, we evaluated the analgesic effect of carbamazepine on this animal model. Carbamazepine is used to treat epilepsy ${ }^{10,11)}$ and paroxysmal pain syndromes, such as trigeminal neuralgia ${ }^{12-14)}$. However, the mechanism by which carbamazepine manifests its analgesic effect in these disorders is unknown. Some articles have reported the efficiency of carbamazepine in painful conditions ${ }^{15,16)}$. However, these reports have described only acute experiments. No chronic animal experiments have been reported. Therefore, we investigated the change in pain thresholds in the chronic state and the effect of carbamazepine on chronic pain using a long-lasting pain animal model.

The purposes of the present study were 1) to develop a model of trigeminal neuralgia in the ophthalmic division (V1) and 2) to confirm the therapeutic effect of carbamazepine using the present model.

\section{Materials and Methods}

We gave careful consideration to the number of animals used and to the duration of their exposure to the neuropathic conditions of this experiment.

\section{Animals}

Twenty-seven adult male Wistar rats (250 to $300 \mathrm{~g}$ ) were used in the experiments. The animals were housed under standard laboratory conditions for several days before the experiments. After surgery they were housed in individual cages until their wounds healed.

Surgery

The rats $(n=27)$ were anesthetized with sodium pentobarbital $(50 \mathrm{mg} / \mathrm{kg}$, intraperitoneally, supplemented as necessary). The right supraorbital nerve was exposed in the orbit. Two ligatures $2 \mathrm{~mm}$ apart were made loosely around the unilateral supraorbital nerve with 4-0 silk ( $n=21$, experimental group). Control animals underwent a sham operation $(n=6$, sham group) in which the nerve was only exposed. In the experimental group, carbamazepine was administered to 15 rats (carbamazepine group) intraperitoneally every day for 10 days from the 10th postoperative day. The remaining 6 rats (ligation group) were not treated with this drug. A diagram of the supraorbital nerve is shown in Figure 1.

\section{Chemicals}

Carbamazepine donated by Ciba Geigy (Basel, Switzerland) was suspended in propylene glycol. One milliliter of a carbamazepine suspension was administered intraperitoneally every day from the 10 th postoperative day. The daily doses were adjusted to $5 \mathrm{mg} / \mathrm{kg}(\mathrm{n}=5)$, $10 \mathrm{mg} / \mathrm{kg}(\mathrm{n}=5)$, and $15 \mathrm{mg} / \mathrm{kg}(\mathrm{n}=5)$.

\section{Behavioral testing}

\section{1) Observation of free behavior}

We observed each animal's behavior for 15 minutes every 10 days and measured body weight every 10 days. Rats were placed in separate cages. Free behavior was observed. Behavioral activity was scored according to four behavioral categories: exploratory behavior, unilateral face grooming, freezing behavior, and abnormal body grooming.

2) Response to two kinds of nociceptive stimulation on the face (pain threshold)

These tests were conducted to assess changes in response to heat and mechanical stimulation, 


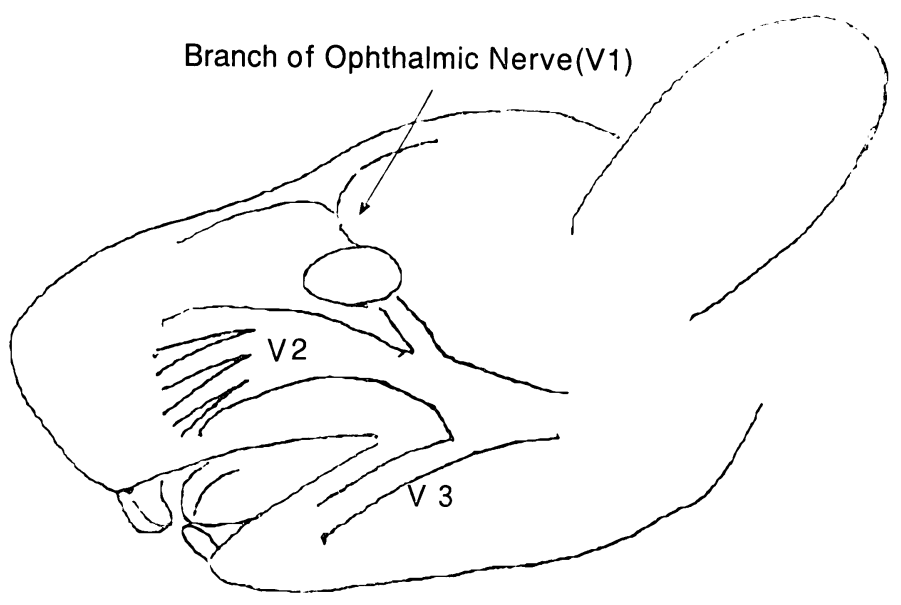

Fig. 1. Supraorbital nerve ligation in the rat.

\section{a) Heat stimulation}

As a heat source, we used a lamp from the condenser of a microscope. The latent time until avoidance movement from the radiant heat focused on the ophthalmic region was measured bilaterally. The voltage loading to the lamp was adjusted to $4.7 \mathrm{~V}$ with a voltslider. The control latency before surgery was $3.5 \pm 0.2$ seconds (mean $\pm S E, n=54$ ). The percent change from control latency was calculated.

\section{b) Mechanical pressure stimulation}

Mechanical pressure on the bilateral ophthalmic regions was applied through a focal pressure apparatus that had a round tip $2 \mathrm{~mm}$ in diameter. The pressure of mechanical stimulation which caused avoidance movement was measured with a force transducer.

The thresholds of the two kinds of pain were observed for 40 days in both the control group $(n=6)$ and the ligation group $(n=6)$. In the carbamazepine group $(n=15)$ heat stimulation was applied for 20 days.

\section{Data analysis}

Statistical analysis was performed with Student's $t$-test. $P$ values less than 0.05 were considered to indicate statistical significance.

\section{Results}

The wounds of all rats healed without complications or inflammatory changes. No particular behavioral changes were observed during the test period in any of the animals. Body weights in the carbamazepine group $(15 \mathrm{mg} / \mathrm{kg})$, increased less than those in the other groups (Fig. 2). There were no significant differences in body weight between the other groups. The thresholds to both heat and pressure stimulation were significantly lower on the CCI operation side compared than on the control and sham operation sides (Figs. 3, 4). The percent decreases of the avoidance latency from radiant heat 10,20,30, and 40 days after surgical operation on the intact and CCI sides of CCI rats were 93.2\%, 60.3\%, 65.2\%, and $71.0 \%$ and $59.7 \%, 49.7 \%, 40.5 \%$, and $55.2 \%$, respectively (Fig. 3A). Those on the intact and the sham sides of the sham group were $75.0 \%, 63.7 \%, 75.7 \%$, and $66.4 \%$ and $76.0 \%, 66.7 \%, 64.7 \%$, and $65.2 \%$, respectively (Fig. 3B). The decreases in threshold 


\section{Body Weight of Rats in Experiment of Carbamazepin}

(g)

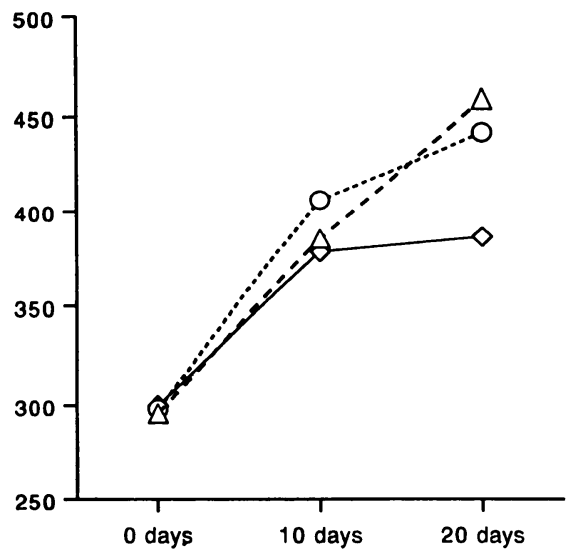

$--\triangle-\quad 5 \mathrm{mg} / \mathrm{kg}(\mathrm{A})$

…… $10 \mathrm{mg} / \mathrm{kg}(B)$

$\checkmark 15 \mathrm{mg} \mathrm{kg}$ (C)

Fig. 2. Increase in body weight carbamazepine was administered by intraperietoneally. The carbamazepine doses used were $5 \mathrm{mg} / \mathrm{kg}$ (line $\mathrm{A}, \mathrm{n}=5$ ), $10 \mathrm{mg} / \mathrm{kg}$ (line $\mathrm{B}, \mathrm{n}=5$ ) and $15 \mathrm{mg} / \mathrm{kg}$ (line $\mathrm{C}, \mathrm{n}=5$ ).

\section{Heat Stimulation}

(A)

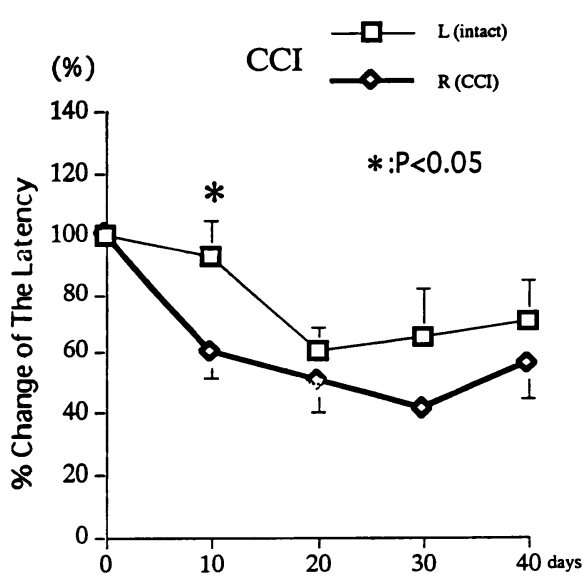

(B)

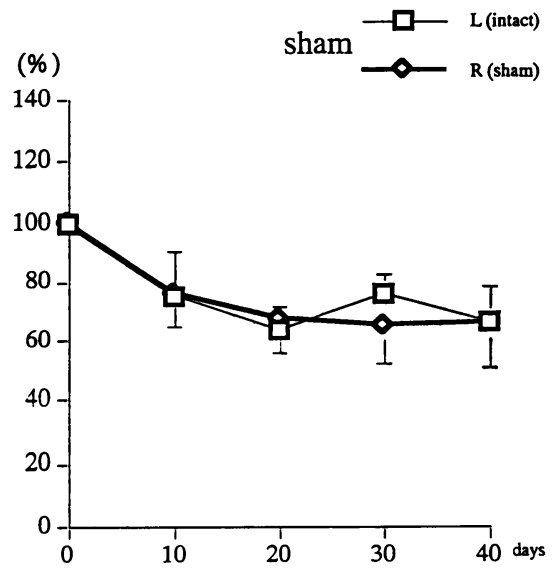

Fig. 3. Heat stimulation: CCI on a branch of the supraorbital nerve decreased avoidance latency for heat stimulation compared with the intact side $(A, n=6)$, but no significant difference was observed in sham operated rats between sham and intact sides $(B, n=6)$.

pressure to cause avoidance behavior $10,20,30$, and 40 days after surgery in the CCI animals were $16.0 \mathrm{~g}, 13.7 \mathrm{~g}, 28.8 \mathrm{~g}$, and $34.3 \mathrm{~g}$ (CCI side) and $37.2 \mathrm{~g}, 24.2 \mathrm{~g}, 31.8 \mathrm{~g}$, and $37.0 \mathrm{~g}$ (intact side), respectively (Fig. 4A). Those in sham animals were $31.5 \mathrm{~g}, 33.5 \mathrm{~g}$, $22.7 \mathrm{~g}$, and $33.3 \mathrm{~g}$ (sham side) and $31.5 \mathrm{~g}, 44.7 \mathrm{~g}, 31.2 \mathrm{~g}$, and $42.3 \mathrm{~g}$ (intact side) respectively (Fig. 4B). 


\section{Pressure Stimulation}

(A)

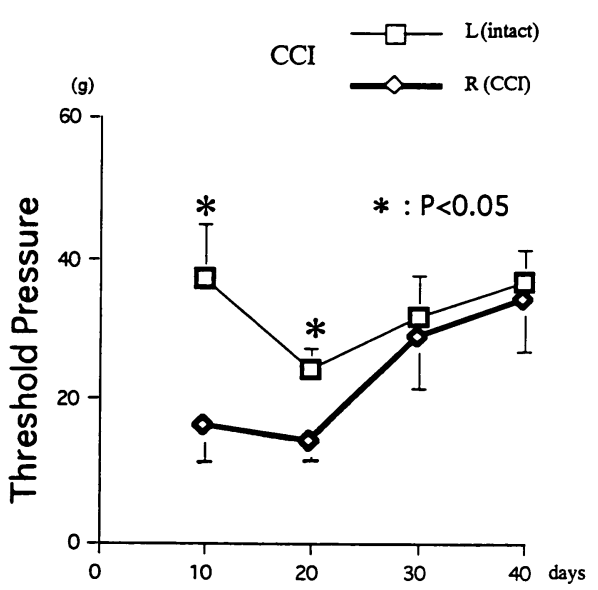

(B)

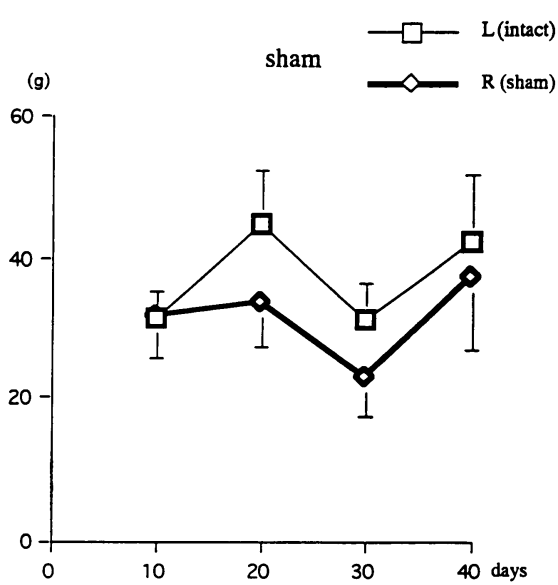

Fig. 4. Pressure stimulation: CCI on the supraorbital nerve decreased avoidance threshold to pressure stimulation compared with the intact side $(A, n=6)$, but no significant difference was observed in sham operated rats between sham and intact sides (B, $\mathrm{n}=6)$.

\section{Heat Stimulation (Carbamazepin)}
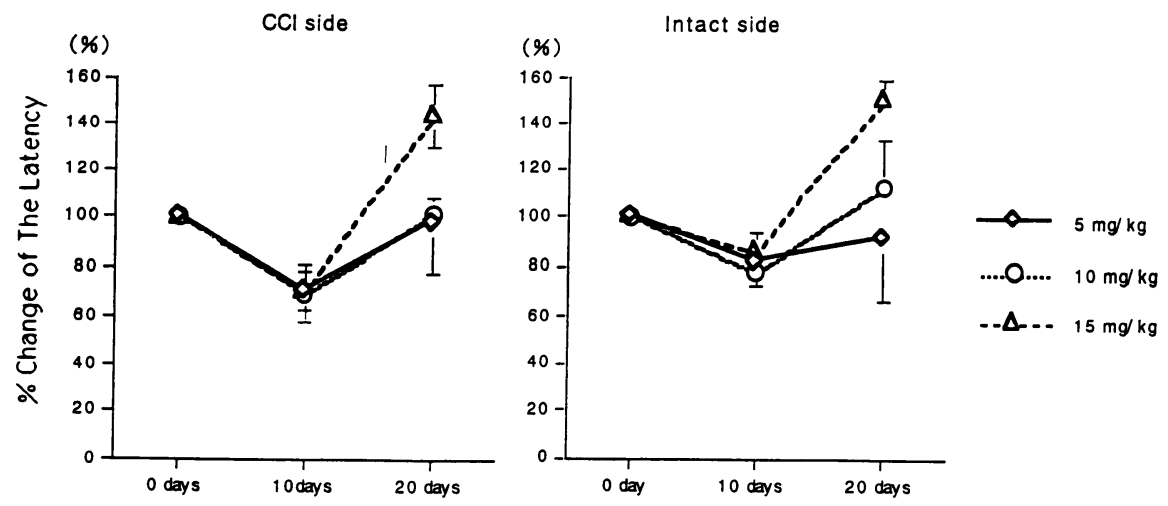

Fig. 5. The analgesic effect of carbamazepine: In the carbamazepine groups the latency of avoidance response to heat stimulation on the intact side was dose-dependently prolonged. However, on the CCI side $5 \mathrm{mg} / \mathrm{kg}$ dose carbamazepine had the same effect as $10 \mathrm{mg} / \mathrm{kg}$.

Avoidance latency of heat stimulation was dose-dependently prolonged on the intact side (Fig. 5). However, on the CCI side a $5 \mathrm{mg} / \mathrm{kg}$ dose of carbamazepine had the same effect as a $10 \mathrm{mg} / \mathrm{kg}$ dose. The percent decreases in avoidance latency 10 and 20 days after surgery in the $5 \mathrm{mg} / \mathrm{kg}, 10 \mathrm{mg} / \mathrm{kg}$ and $15 \mathrm{mg} / \mathrm{kg}$ CCI groups were $70.8 \%$ and $97.4 \%$ 
$(5 \mathrm{mg} / \mathrm{kg}), 70.0 \%$ and $102.0 \%(10 \mathrm{mg} / \mathrm{kg})$, and $70.2 \%$ and $144.0 \%(15 \mathrm{mg} / \mathrm{kg})$, respectively (Fig. 5A). Those in the sham groups were $81.0 \%$ and $91.0 \%(5 \mathrm{mg} / \mathrm{kg}), 77.8 \%$ and $112.0 \%(10 \mathrm{mg} / \mathrm{kg})$ and $85.4 \%$ and $150.8 \%(15 \mathrm{mg} / \mathrm{kg})$, respectively (Fig. 5B).

\section{Discussion}

CCI models of trigeminal nerve injury have been reported by Vos and Maciewicz ${ }^{17)}$ and by Kawamoto ${ }^{18}$. Both these models were produced by constriction of a branch of the infraorbital nerve. In the model of Vos and Maciewicz, prominent hyperalgesia was produced. However, the operation was rather invasive and behavioral abnormalities, such as grooming and weight loss, were observed. In Kawamoto's model, the surgical view was extremely narrow and a fine surgical technique was required. In the present study, loose ligation could be applied to the ophthalmic branch of the trigeminal nerve easily and produced significant hyperalgesia to heat and pressure stimulation (Figs. 3, 4). In the sham group avoidance latency also decreased. However, there was no significant difference between the intact side and the sham side. This decline in latency might not be due to the sham operation but rather to a learning effect. On the tail-flick test with heat stimulation, a similar phenomenon, that is, repeated heat stimuli decreased tail-flick latency, was often observed. The latency also decreased on the intact side of the CCI group but decreased further on the CCI side.

In humans, carbamazepine is effective against trigeminal neuralgia ${ }^{14)}$. However, the mechanism by which carbamazepine achieves pain relief in this disorder is unknown. Few reports of carbamazepine's effects in the chronic state have been published. Foong et al. ${ }^{15)}$ reported that carbamazepine and phenytoin were effective against acute trigeminal hyperalgesia due to paint-producing substances. Burchiel ${ }^{16)}$ reported that carbamazepine was effective against saphenous neuromas: in this report, 2.51 to $11.2 \mathrm{mg} / \mathrm{kg}$ of carbamazepine inhibited spontaneous activities of $A \delta$ fibers. The present results suggest that low-dose carbamazepine is also effective against chronic pain (Fig. 5).

The major pathophysiologic theories of trigeminal neuralgia have emphasized either a peripheral or central mechanism. However, these theories are controversial. Most cases of trigeminal neuralgia are caused by compression of the trigeminal nerve by vessels or tumors. In our model trigeminal neuralgia is not produced by vascular compression but by surgical suture. However, we believe that our model closely simulates conditions of nerve compression. A characteristic feature of trigeminal neuralgia is its pattern of exacerebations and remissions. Most patients start by experiencing typical brief paroxyms of pain triggered by stimulation of an area of skin or mucous membrane. In our model spontaneous and continuous pain was not observed. However, pain was produced by weak stimulation. Furthermore, that the carbamazepine was effective suggests that the present animal model is appropriate for studying human neuralgia. Our method produces trigeminal neuralgia relatively easily and might be useful for investigating the pathophysiology, etiology, and treatment of trigeminal pain.

\section{References}

1) Bennett GJ and Xie YK: A peripheral mononeuropathy in rat that produces disorders of pain sensation like those seen in man. Pain, 33: 87-107 (1988)

2) Attal N, Jazat F, Kayser V and Guilbaud G: Further evidence for "pain-related" behaviours in a modẹl of unilateral mononeuropathy. Pain, 41: 235-51 (1990) 
3) Gautron M, Jazat F, Ratinahirana H, Hauw JJ and Guilbaud G: Alterations in myelinated fibers in the sciatic nerve of rats after constriction: possible relationships between the presence of abnormal small myelinated fibers and behaviour. Neurosci Lett, 111: 28-33 (1990)

4) Basbaum AI, Gautron M, Jazat F, Mayes M and Guilbaud G: The spectrum of fiber loss in a model of neuropathic pain in the rat: an electron microscopic study. Pain, 47: 359-367 (1991)

5) Munger BL, Bennett GJ and Kajander KC: An experimental painful peripheral neuropathy due to nerve constriction. I. Axonal pathology in the sciatic nerve. Exp Neurol, 118: 204-214 (1992)

6) Nuyttenu D, Kupers R, Lammens M, Dom R, van Hees J and Gybels J: Further evidence for myelinated as well as unmyelinated fiber damage in a rat model of neuropathic pain. Exp Brain Res, 91: 73-78 (1992)

7) Tanck EN, Kroin JS, McCarthy RJ, Penn RD and Ivankovich AD: Effects of age and size on development of allodynia in a chronic pain model produced by sciatic nerve ligation in rats. Pain, 51: 313-316 (1992)

8) Coggeshall RE, Dougherty PM, Pover CM and Carlton SM: Is large myelinated fiber loss associated with hyperalgesia in a model of experimental peripheral neuropathy in the rat? Pain, 52: 233-242 (1993)

9) Guilbaud G, Gautron M, Jazat F, Ratinahirana H, Hassig R and Hauw JJ: Time course of degeneration and regeneration of myelinated nerve fibers following chronic loose ligatures oft he rat sciatic nerve: can nerve lesions be linked to the abnormal pain-related behaviors? Pain, 53: 147-158 (1993)

10) Albright PS and Wauquier A: Development of a new pharmacological seizure model: effects of anticonvulsants on cortical and amygdala-kindled seizures in the rat. Epilepsia, 21: 681-689 (1980)

11) Ashton D and Wauquir A: Behavioral analysis of the effects of 15 anticonvulsants in the amygdaloid kindled rat. Psychopharmachology, 65: 7-13 (1979)

12) Bondule M: Current approaches to the treatment of trigeminal neuralgia. In W. Birkmayer (Ed), Epileptic Sezures-Behavior Pain, Huber, Bern, pp 321-326 (1976)

13) Cereghino JJ, Brock JT, Van Meter JC, Penry JN, Smith LD and White BG: Carbamazepine for epilepsy: a controlled prospective evaluation. Neurology, 24: 401-410 (1974)

14) Blom S: Trigeminal neuralgia: Its treatment with a new anticonvulsant drug (G-32883). Lancet, 1: 839-840 (1962)

15) Foong FW, Satoh $\mathbf{M}$ and Takagi H: A newly devised reliable method for evaluating analgesic potencies of drugs on trigeminal pain. Journal of Pharmacological Methods, 7: 271-278 (1982)

16) Burchiel $\mathrm{KJ}$ : Carbamazepine inhibits spontaneous activity in experimental neuromas. Experimental Neurology, 102: 249-253 (1988)

17) Vos B and Maciewicz R: Behavioral changes following ligation of the infraorbital nerve in rat: An animal model of trigeminal neuropathic pain. In Lesions of Primary Afferent Fibers as a Tool for the Study of Clinical Pain (Ed. by Bessen JM and Guilband G), Eicepta Medica, Amsterdam, pp 147-158 (1991)

18) Kawamoto $\mathrm{H}$ : Behavioral and Immunohistochemical studies in rats with a trigeminal mononeuropathy. Kyushuusikaisi, 47(1): 222-234 (1993) (in Japanese)

[Received February 1, 1997: Accepted February 21, 1997] 